\title{
DÜBLIN
}

Technological University Dublin

ARROW@TU Dublin

\section{High Performance Modified DSR Routing Protocol for WLAN Mesh Networks}

\author{
Mustafa Ramadhan \\ Technological University Dublin, mustafa.ramadhan@tudublin.ie \\ Mark Davis \\ Technological University Dublin, mark.davis@tudublin.ie
}

Follow this and additional works at: https://arrow.tudublin.ie/commcon

Part of the Electrical and Computer Engineering Commons

\section{Recommended Citation}

Ramadhan, M. \& Davis, M. (2010) High Performance Modified DSR Routing Protocol for WLAN Mesh Networks. IWCMC 2010. The 6th International Wireless Communications \& Mobile Computing Conference, Caen, France. 2010.

This Conference Paper is brought to you for free and open access by the Communications Network Research Institute at ARROW@TU Dublin. It has been accepted for inclusion in Conference papers by an authorized administrator of ARROW@TU Dublin. For more information, please contact arrow.admin@tudublin.ie, aisling.coyne@tudublin.ie,gerard.connolly@tudublin.ie.

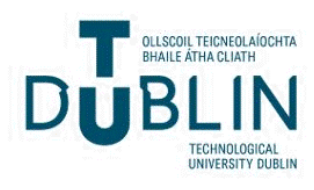




\title{
Antenna \& High Frequency Research Centre Conference Papers
}

\section{High Performance Modified DSR Routing Protocol for WLAN Mesh Networks}

\author{
Mustafa Ramadhan* Mark Davis ${ }^{\dagger}$
}

*Dublin Institute of Technology, mustafa.ramadhan@cnri.dit.ie

†Dublin Institute of Technology, mark.davis@dit.ie

This paper is posted at ARROW@DIT.

http://arrow.dit.ie/ahfrccon/15 


\section{— Use Licence}

\section{Attribution-NonCommercial-ShareAlike 1.0}

You are free:

- to copy, distribute, display, and perform the work

- to make derivative works

Under the following conditions:

- Attribution.

You must give the original author credit.

- Non-Commercial.

You may not use this work for commercial purposes.

- Share Alike.

If you alter, transform, or build upon this work, you may distribute the resulting work only under a license identical to this one.

For any reuse or distribution, you must make clear to others the license terms of this work. Any of these conditions can be waived if you get permission from the author.

Your fair use and other rights are in no way affected by the above.

This work is licensed under the Creative Commons Attribution-NonCommercialShareAlike License. To view a copy of this license, visit:

- URL (human-readable summary):

http://creativecommons.org/licenses/by-nc-sa/1.0/

- URL (legal code):

http://creativecommons.org/worldwide/uk/translated-license 


\section{High Performance Modified DSR Routing Protocol for WLAN Mesh Networks}

\author{
Mustafa Ramadhan \\ Communications Network Research \\ Institute, School of Electronic and \\ Communications Engineering, Dublin \\ Institute of Technology \\ Dublin, Ireland \\ mustafa.ramadhan@cnri.dit.ie
}

\author{
Mark Davis \\ Communications Network Research \\ Institute, School of Electronic and \\ Communications Engineering, Dublin \\ Institute of Technology \\ Dublin, Ireland \\ mark.davis@dit.ie
}

\begin{abstract}
This work presents a cross-layer modification to the $D S R$ protocol which discovers high throughput paths on multi-hop wireless mesh networks. The modified DSR incorporates a metric based upon the bandwidth availability at a node into the routing discovery mechanism. We introduce the Access Efficiency Factor $(A E F)$ as an alternative metric to the hop-count for the routing selection mechanism. In this modification, the selected path is identified by finding a path with the highest minimum $A E F$ value. The OPNET modeler has been employed to investigate the performance of the modified $D S R$ protocol on randomly generated network topologies of different node densities. Our results suggest that employing the $A E F$ as a routing discovery metric can significantly increase the average global throughput of wireless mesh networks.
\end{abstract}

\section{Categories and Subject Descriptors}

C.2.1: COMPUTER-OMMUNICATION NETWORKS: Network Architecture and Design, Wireless communication; Network communications

\section{General Terms}

Algorithms, Performance, Design.

\section{Keywords}

$D S R$ Protocol; Routing Mechanism; MAC Mechanism; WMN.

\section{INTRODUCTION}

Wireless mesh networks (WMNs) have attracted the attention of networking industries due to their many desirable characteristics such as multi-hop routing, self-configuration, self-organization, bandwidth fairness, low cost, easy deployment. WMNs consist of two types of nodes: mesh routers and mesh clients. Mesh routers

Permission to make digital or hard copies of all or part of this work for personal or classroom use is granted without fee provided that copies are not made or distributed for profit or commercial advantage and that copies bear this notice and the full citation on the first page. To copy otherwise, or republish, to post on servers or to redistribute to lists, requires prior specific permission and/or a fee.

Conference'10, Month 1-2, 2010, City, State, Country.

Copyright 2010 ACM 1-58113-000-0/00/0010...\$10.00. have minimal mobility and contain in addition to the routing capability for gateway/bridge functions additional routing functions to maintain the mesh network. They provide integration with other networks such as the Internet, cellular, etc. and also provide network access for both mesh and conventional clients. Mesh routers are usually equipped with multiple wireless interfaces with the same or different wireless access technologies in order to improve flexibility. Mesh clients can be either stationary or mobile. They are usually equipped with a single wireless interface

Mesh clients can form a mesh network among themselves and with mesh routers [1]. Mesh clients can also act as a router for mesh networking.

In wireless network, routing protocols play an important role in managing the formation, configuration, and maintenance of the topology of the network [2]. Routing metric defined by the protocols are responsible for establishing the paths in the network. The routing problem in WMNs is generally concerned with finding a good path between the source and the destination nodes. It generally focuses on multiple objectives to be optimized, such as path capacity (which refers to the number of bits per second (bps) that can be sent along the path between the source and the destination nodes) and end-to-end delay.

Many link quality routing algorithms for WMNs have been proposed such as the Expected Transmission Count $(E T X)$ to determine the quality of a route [3]. ETX measures the expectation number of a successful transmission for sending a packet a cross a link. The metric highlights the impact of link loss ratios. The drawback with this metric it that, it does not lead to good paths when the link qualities vary. Draves et. al developed the Expected Transmission Time (ETT) metric [4]. The ETT depends on the loss rate and the bandwidth of each link. The ETT is more effective than hop-count but it does not consider the interference that might be caused by a single link with high loss rate along a path which can cause a dramatic reduction in the overall path performance. Also the ETT does not consider the MAC overhead delays. In order to optimize the path capacity and the end-to-end delay, the Weighted Cumulative Expected Transmission Time (WCETT) was proposed [5]. Like ETX and ETT, WCETT does not take into account interflow interference, link load or link congestion when establishing paths [6]. Yang et al proposed 
similar metrics to WCETT in order to capture the interflow interference [7]. While Zhou et al used the WCETT metric to quantify the intraflow interference [8]. Kyasanur et al suggested a link layer protocol for channel assignment and a routing metric that expands WCETT for cases where the switching of interfaces is necessary [9]. The metric is intended to capture the delay when sending a packet and switching an interface from one channel to another. Iannone et al identified the link cost as the inverse of its transmission rate and showed that the throughput can be improved with respect to the hop count metric by finding low-cost paths [10].

A routing algorithm that takes into account the variability of the wireless link quality is required. To achieve this awareness, a cross-layer technique should be employed for routing in order to find reliable and efficient paths to enhance the performance of the network. The objective of this approach is to provide the routing layer with view information at other layers in order to obtain an improvement in the network performance. This work proposes a cross-layer approach that employs MAC layer information at the network layer in order to find high throughput routes between the source and the destination nodes in the network. This is achieved by using the information regarding local availability of bandwidth at the node which is defined through the Access Efficiency Factor $(A E F)$ as the routing metric. By finding paths with large available bandwidths one can optimize the path capacity and hence optimize the global throughput of the network. In this work, we have examined the performance of this new routing metric in networks of different node densities.

The rest of this paper is organized as follows: Section 2 gives an overview of routing in WMNs and discusses the needs of adaptive routing. The definition of the Access Efficiency Factor $(A E F)$ is presented in section 3. An overview of the computer simulation setup is introduced in section 4 . Section 5 discusses the network performance and the results of our modified protocol. Finally, we conclude the work and present our plan for the future work in section 6 .

\section{PERFORMANCE METRIC}

Routing over wireless mesh networks is a complex problem due to the variations in link quality, even when nodes are static. The most widely used routing metric for WMNs for finding the routing path is the hop-count metric. It has been shown that the hop-count metric is not an efficient metric for many situations as it does not consider the variability of the wireless link. For example, under congested conditions, the hop-count metric will not be an accurate performance metric. . Couto et al showed that routing in multi-hop wireless networks using the hop-count metric is not effective for finding good paths as it is not able to effectively transport data with reasonable delay, throughput and reliability[11]. Gupta et al also demonstrated that routing algorithms which ignore factors such as interference can result in reduced network throughputs [12]. A key challenge in WMNs is the need for an efficient protocol that determines a path according to a certain performance metrics related to the link quality. However, the hop-count metric ignores the wireless link variability. A widely used routing protocol that uses the hopcount metric is the Dynamic Source Routing (DSR) protocol. The $D S R$ protocol operates on-demand and employs an efficient route discovery mechanism. Route discovery packets are used to determine the route from source to destination. Routed packets contain the address of each node it traverses in order to get to its destination.

When a node in the network using the $D S R$ routing protocol attempts to send a packet to a destination node. It first queries its Route Cache Table where the previously discovered routes are reserved. If there is no route found in its cache, the sender node initiates route discovery procedure to find a new route to the destination node.

The route discovery procedure functions as follows: the sender node broadcasts a Route Request packet. Each node receiving a request message rebroadcasts it unless it is the destination or it has a route to the destination in its route cache. Each Route Request packet carries the identifications of the source and the destination nodes, unique request identification and a list of the addresses of the intermediate nodes, by which that Route Request packet has been forwarded. When the destination node receives this Route Request message, it returns a Route Reply message to the source node containing the path taken by the route request message. When the source node receives this route reply message, it caches the path in its route cache in order not to repeat the route discovery process for each new packet destined to the same target node, for more details see [13].

The $D S R$ protocol fails to take account of link quality parameters like the local availability of bandwidth at a node which has an important impact in WMNs based upon the IEEE 802.11 WLAN standard. In order to make the DSR protocol better suited to the WMN environment, we take into account the local availability of bandwidth at each node in the network. This modification can be done by replacing the hop-count metric with an access efficiency factor metric that provides an indicator of the availability of bandwidth. The objective of this modification is to incorporate knowledge of the path capacity into the route discovery mechanism. The strategy behind this modification is to find the optimal path by selecting the path with the highest minimum $A E F$ value.

\section{ACCESS EFFIECIENCY FACTOR $(A E F)$}

The $A E F\left(\eta_{f}\right)$ is a measure of how efficiently a station contends for access to the wireless medium. It is based on the normalized $B W_{\text {access }}$ and $B W_{\text {load }}$ parameters. $B W_{\text {load }}$ represents the portion of the transmission rate required by the station for transmitting its load and can be defined as follows [14]:

$$
B W_{\text {load }}=\frac{T_{\text {load }}}{T_{\text {busy }}+T_{\text {idle }}}
$$

While $B W_{\text {access }}$ represents the portion of the transmission rate required by the station to win access opportunities for its load and can be shown as follows:

$$
B W_{\text {access }}=1-B W_{\text {busy }}
$$

$T_{\text {busy }}$ and $T_{\text {idle }}$ are expressed as follows [14]:

$$
T_{b u s y}=\sum_{i} T_{b u s y}^{(i)}
$$




$$
T_{\text {idle }}=\sum_{i} T_{\text {idle }}^{(i)}=1-T_{\text {busy }}
$$

Where $T_{\text {busy }}^{(i)}$ and $T_{i d l e}^{(i)}$ are the durations of the $i^{\text {th }}$ busy and idle intervals respectively within the measurement interval of interest. $B W_{b u s y}$ can be defined as follows:

$$
B W_{\text {busy }}=\frac{T_{\text {busy }}}{T_{\text {busy }}+T_{\text {idle }}}
$$

The $A E F$ is based on the Access Efficiency $\left(\eta_{a}\right)$ parameter and is defined as [14]:

$$
\eta_{a}=\frac{B W_{\text {load }}}{B W_{\text {access }}}
$$

In calculating the capacity, at the saturation condition when all the free time is used to support the station's load:

$$
B W_{\text {load }}^{(\text {sat })}+B W_{\text {access }}=1
$$

Substituting (6) in (7):

$$
B W_{\text {load }}^{(\text {sat })}+\frac{B W_{\text {load }}^{(\text {sat })}}{\eta_{a}}=1
$$

Equation (8) can be rewritten as follows:

$$
B W_{\text {load }}^{(\text {sat })}\left(\frac{\eta_{a}+1}{\eta_{a}}\right)=1
$$

By defining the $A E F$ as:

$$
\eta_{f}=\frac{\eta_{a}}{1+\eta_{a}}
$$

Equation (9) can be written as follows:

$$
\eta_{f}=B W_{\text {load }}^{(\text {sat })}
$$

In the equation (11), $\eta_{f}$ corresponds to the maximum load achieved by a station under ideal network conditions, i.e. when no other stations are present. For the general case where there is more than one station present in the network:

$$
T_{p} \propto B W_{\text {load }}^{(\text {sat })} \propto \eta_{f}
$$

Where $T_{p}$ is the station's throughput and $B W_{\text {load }}^{(\text {sat })}$ is the saturated load of the station. Equation (12) states that the bigger $\eta_{f}$ is the bigger saturated $B W_{\text {load }}$ and hence the bigger the $T_{p}$.

\section{SIMULATION SETUP}

We have examined the performance of the network for different topologies with the modified $D S R$ against the standard $D S R$ protocol. The OPNET modeler is utilized to simulate the performance of the modified $D S R$ protocol. The node traffic was generated using Poisson traffic sources with a rate of 5 packets per second. Packet sizes are set to 512 bytes.

In this work, we have investigated the performance of different wireless network scenarios of different node densities factors $(D F$ $=1,2,4,6,8,10)$ by comparing the modified $D S R$ protocol against the standard $D S R$. We define a node density factor $(D F)$ as follows.

$$
D F=\pi \mathrm{R}^{2} * D-1
$$

Where $R$ is the transmission range of the node in the network and $D$ is the node density:

$$
D=\frac{\text { Number_of_Nodes }}{\text { Area }}
$$

Where Area is the size of the area of the network. $D F$ represents the number of nodes lie in the transmission range of the sender. The factor -1 in equation (13) represents the sender node itself. In this work we have generated 1000 random topologies for each scenario with one receiver (gateway) and 99 senders. The simulator was run twice for each topology, once with the standard $D S R$ followed by the modified $D S R$. The average throughput was recorded for each run over 10 minute intervals in order to calculate the percentage improvement for the particular topology. For each scenario the complementary cumulative distribution function (CCDF) of the throughput improvement and the delay increase for all network topologies examined have been calculated. The CCDF provides for a statistical characterisation of the improvement in the throughput and the increment in the delay produced by the modified $D S R$ algorithm.

\section{NETWORK PERFORMNCE AND RESULTS}

The goal of this work is to analyze the performance of the modified $D S R$ routing protocol against the standard $D S R$ protocol. The analysis focuses on the improvement in the average global throughput and concomitant increase in the average global delay was also analyzed. A modification to the route discovery mechanism has been made which uses new selection criteria. In this modification, the strategy of the algorithm is to determine the optimal path based on the following:

$$
\max _{i}\left\{\min _{k}\left\{\eta\left(l_{k i}\right)\right\}\right\}
$$

Where $l_{k i}$ is a link $\mathrm{k}$ in route $i$. Equation (15) describes the strategy of finding the path with the highest minimum $A E F$ value which attempts to avoid routing through congested areas in the network. Avoiding a congested area will result in a significant improvement in the network performance. A major advantage of this approach is that it employs passive monitoring of the wireless medium and therefore it does not incur the overhead usually associated with active probing.

We have analyzed the performance of the network scenarios for different $D F$ values. The CCDF of the percentage throughput improvement and the delay increment were calculated for the modified $D S R$ against the standard $D S R$, see Figures 1 and 2. 


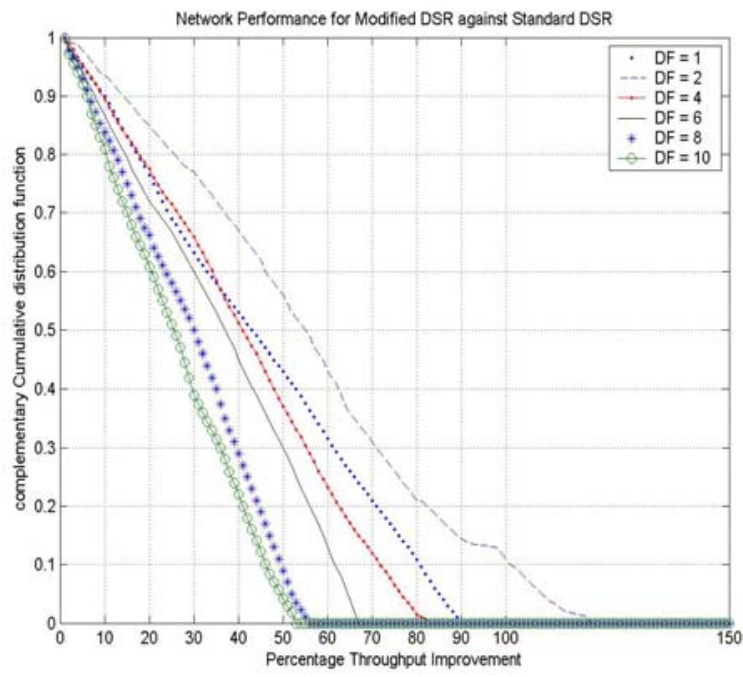

Figure 1. CCDF of the percentage throughput improvement for all examined scenarios of different $D F$ values.

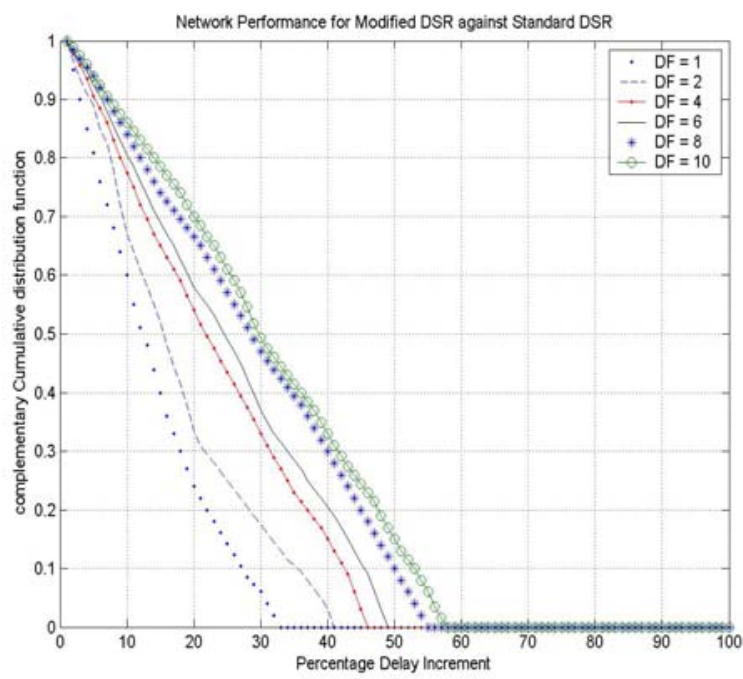

Figure 2. CCDF of the percentage delay increnent for all examined scenarios of different $D F$ values.

By using the CCDF for all the examined test scenarios, we obtained the fraction of stations $\left(F_{r}\right)$ that exhibit a probability of percentage throughput improvement $\left(P_{T}\right)$ greater than or equal to $30 \%$ and $50 \%$, see Table 1 . The fraction of stations $\left(F_{r}\right)$ that exhibits a probability percentage delay increment $\left(P_{D}\right)$ greater than $20 \%, 30 \%$, and $40 \%$ is given in Table 2 .
Table 1. Probability Percentage throughput improvement for all examined scenarios of different $D F$ values.

\begin{tabular}{|c|c|c|}
\hline $\begin{array}{c}\text { Density } \\
\text { Factor } \\
(\boldsymbol{D} \boldsymbol{F})\end{array}$ & \begin{tabular}{c}
$\boldsymbol{P}_{\boldsymbol{T}}\left[\begin{array}{c}\text { Improvement } \geq \\
\mathbf{3 0} \%]\end{array}\right.$ \\
\hline 1
\end{tabular}$\quad \boldsymbol{P}_{\boldsymbol{T}}\left[\begin{array}{c}\text { Improvement } \geq \\
\mathbf{5 0} \%]\end{array}\right.$ \\
\hline 2 & $63 \%$ & $43 \%$ \\
\hline 4 & $77 \%$ & $56.5 \%$ \\
\hline 6 & $66 \%$ & $37 \%$ \\
\hline 8 & $60 \%$ & $30 \%$ \\
\hline 10 & $50 \%$ & $9 \%$ \\
\hline
\end{tabular}

Table 2. Probability Percentage delay increment for all examined scenarios of different $D F$ values.

\begin{tabular}{|c|c|c|c|}
\hline $\begin{array}{c}\text { Density } \\
\text { Factor } \\
(\boldsymbol{D F})\end{array}$ & $\begin{array}{c}\boldsymbol{P}_{\boldsymbol{D}}[\text { Increment } \\
\mathbf{2 0 \%}\end{array}$ & $\begin{array}{c}\boldsymbol{P}_{\boldsymbol{D}}[\text { Increment } \\
\mathbf{3 0 \%}]\end{array}$ & $\begin{array}{c}\boldsymbol{P}_{\boldsymbol{D}}[\text { Increment } \\
\mathbf{3 4 0 \%}]\end{array}$ \\
\hline 1 & $24 \%$ & $6 \%$ & $0 \%$ \\
\hline 2 & $33.5 \%$ & $16 \%$ & $3 \%$ \\
\hline 4 & $54 \%$ & $33 \%$ & $16 \%$ \\
\hline 6 & $57.5 \%$ & $37 \%$ & $21 \%$ \\
\hline 8 & $66 \%$ & $47 \%$ & $30 \%$ \\
\hline 10 & $70 \%$ & $49 \%$ & $33 \%$ \\
\hline
\end{tabular}

Using Table 1 we have plotted the relationship between the node density factor $D F$ and the percentage fraction of stations that exhibit throughput improvement greater than $30 \%$ and $50 \%$, see Figure 3. We also plot the relationship between the $D F$ and the percentage fraction of stations that exhibits increment in the delay greater than $20 \%, 30 \%$, and $40 \%$, see Figure 4 . Figure 3 shows that the highest $F_{r}$ value occurs at $D F=2$. In Figure 3, when the $D F$ value exceeds 2 the $F_{r}$ value decreases which means that an increased number of interfering nodes results in a reduction in the percentage fraction of stations that exhibit throughput improvement greater than $30 \%$ and $50 \%$. We can also observe from Figure 3 that reducing the value of the $D F$ to less than 2 results in a reduction in $F_{r}$ because of the reduced level of connectivity. Reduced connectivity also results in a reduction in the average throughput improvement. In Figure 4, as the $D F$ value is increased the percentage fraction of stations that exhibit delay increments greater than $20 \%, 30 \%$, and $40 \%$ are also increased. This is because increasing the number of interfering nodes results in an increase in the average global delay time of the network. 


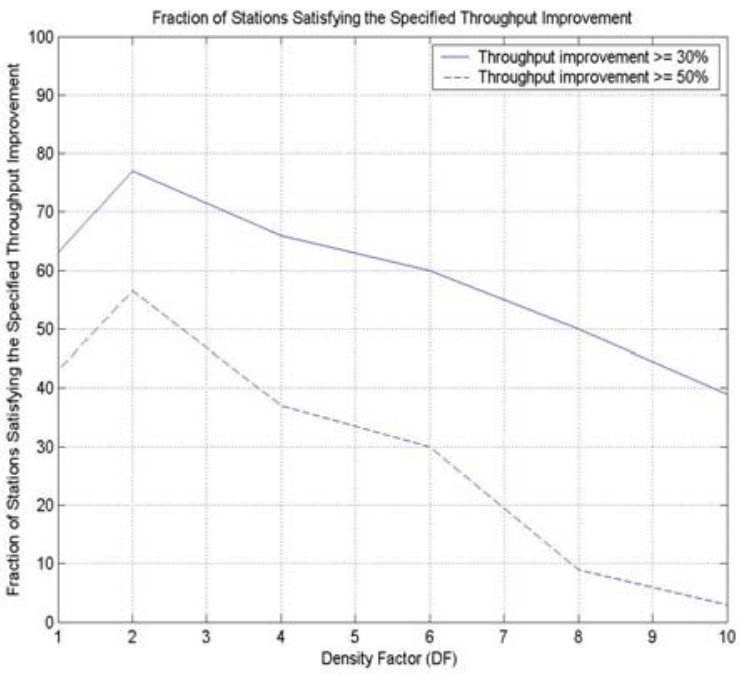

Figure 3. Probability of percentage throughput improvement as a function of node density factor.

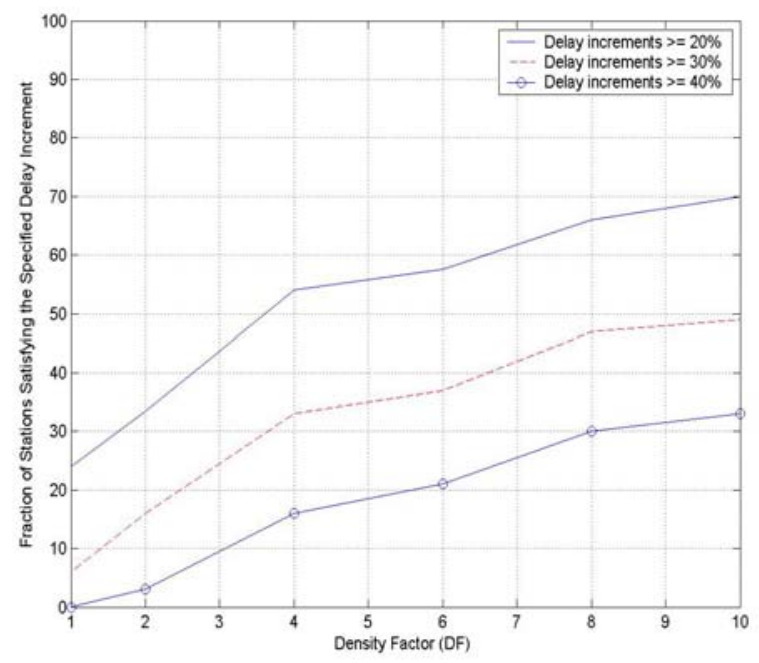

Figure 4. Probability of percentage delay increment as a function of node density factor.

In all the simulation scenarios considered it has been shown that employing $A E F$ as a metric in the route discovery mechanism of the $D S R$ protocol significantly improves the average global throughput of the topology. This improvement in the average global throughput of the network is accompanied by an increase in the global delay time.

\section{CONCLUTION AND FUTURE WORK}

We have modified the $D S R$ protocol to make it better suited to the WMN environment. In this modification, we have replaced the hop-count metric with a metric that reflects the local availability of bandwidth at a node. This is an important issue in IEEE 802.11 WLAN networks where users must contend for access. Including the $A E F$ metric (which is a measure to the local availability of the bandwidth at a node into the routing algorithm) in the routing mechanism will increase significantly the overall performance of the network. The objective of our modification is to identify the highest throughput path by finding a path with the highest minimum $A E F$ value.

Simulations performed on OPNET modeler for different network scenarios of different node densities show that our modified $D S R$ protocol significantly increases the global throughput of the networks by determining the routes with higher throughputs than a minimum hop-count metric, particularly with paths of two or more hops.

Our future work is to modify the $D S R$ protocol by incorporating hop-count metric in addition to the $A E F$ metric and compare the global throughput improvement of this protocol with currently modified $D S R$ protocol. We also are planning to investigate the effect of the variation of the hop-count limit on the network performance for the modified $D S R$ protocol against the standard $D S R$. The aim of using hop-count metric in addition to the $A E F$ is to control the end-to-end delay time in the network. Varying the hop-count limit will allow the network manager to tune to satisfy any maximum delay requirements.

\section{REFERENCES}

[1] J. Li, C. Blake, D. D. Couto, H. I. Lee, and R. Morris, "Capacity of Ad Hoc Wireless Networks," in Proc. 7th ACM International Conference on Mobile Computing and Networking (MOBICOM), pages 61-69, Rome, Italy, July 2001.

[2] P. Hu, R. Robinson, M. Portmann, and J. Indulska, "Context-Aware Routing in Wireless Mesh Networks," In Proceedings of the 2nd ACM International Workshop on Context-Awareness for Self-Managing Systems (CASEMANS), (Pervasive'08 Workshop), May 22, 2008, Sydney, Australia.

[3] D.S.J. De Couto, D. Aguayo, J. Bicket, R. Morris, "A highthroughput path metric for multi-hop wireless routing," in: ACM Annual International Conference on Mobile Computing and Networking (MOBICOM), 2003, pp. 134 146.

[4] R. Draves, J. Padhye, and B. Zill, "Routing in multi-radio, multi-hop wireless mesh networks," in MobiCom '04: Proceedings of the 10th annual international conference on Mobile computing and networking. New York, NY, USA: ACM Press, 2004, pp. 114-128.

[5] R. Draves, J. Padhye, B. Zill, "Comparisons of routing metrics for static multi-hop wireless networks," in: ACM Annual Conference of the Special Interest Group on Data Communication (SIGCOMM), August 2004, pp. 133- 144.

[6] A. A. Pirzada, M. Portmann, R. Wishart, J. Indulska, "SafeMesh: A wireless mesh network routing protocol for incident area communications”, Pervasive and Mobile Computing, vol 5, no 2, (2009) 201_221.

[7] Y. Yang, J. Wang, and R. Kravets, "Interference-aware Load Balancing for Multihop Wireless Networks", Technical 
Report UIUCDCS-R-2005-2526, Dept. of Computer Science, Univ. of Illinois at Urbana-Champaign, 2005.

[8] W. Zhou, D. Zhang, D. Qiao, Comparative study of routing metrics for multi-radio multi-channel wireless networks, WCNC 2006, Las Vegas.

[9] P. Kyasanur and N. H. Vaidya, "Routing and link-layer protocols for multi-channel multi-interface ad hoc wireless networks,” SIGMOBILE Mob. Comput. Commun. Rev., vol. 10, no. 1, pp. 31-43, 2006, New York, NY, USA.

[10] L. Iannone, K. Kabassanow, S. Fdida, "Evaluation of crosslayer rate-aware routing in a wireless mesh network test bed,” Eurasip journal on wireless communications and networking, vol 2007, Article Id 86510.

[11] D.S.J. De Couto, D. Aguayo, B.A. Chambers, and R. Morris, "Performance of multi-hop wireless networks: Shortest path is not enough,” Proceedings of First Workshop on Hot Topics in Networks (HotNets-I), Oct. 2002.

[12] P. Gupta, P.R. Kumar, "The capacity of wireless networks," IEEE Transactions on Information Theory 46 (2), 2000, pp. 388-404.

[13] D. Johnson, D. Maltz, Y. Hu, and J. Jetcheva,” The dynamic source routing protocol for mobile ad hoc networks," Internet Draft, Internet Engineering Task Force, Mar. 2001. http://www.ietf.org/internetdrafts/draft-ietf.

[14] M. Davis, “A Wireless Traffic Probe for Radio Resource Management and QoS Provisioning in IEEE 802.11

WLANs," ACM Symposium on Modeling, Analysis and Simulation of Wireless and Mobile Systems (MSWiM'04), Oct. 2004, Venezia, Italy. 